\title{
INHIBITION OF PROSTAGLANDIN BIOSYNTHESIS BY EICOSAPENTAENOIC ACID
}

Brenda R. Culp, Bradley G. Titus and William E.M. Lands, Departments of Internal Medicine (Cardiology Division) and Biological Chemistry, The University of Michigan, Ann Arbor, MI 48109 (Reprint Request to BRC)

\section{ABSTRACT}

Eicosapentaenoic acid [20:5(n-3)] is not oxidized by the purified cyclooxygenase from sheep vesicular glands in the conditions of low peroxide tone in which arachidonate $[20: 4(n-6)]$ is rapidly oxygenated. When the level of peroxide in incubation mixtures is allowed to rise, there is a dramatic change in reactivity of the cyclooxygenase to react with 20:5(n-3) at one-half the rate and one-third the extent observed with 20:4(n-6). Overall, the low peroxide levels expected in vivo would most probably cause the $(n-3)$ type of fatty acid to be a general inhibitor of prostaglandin formation, through both reversible and irreversible actions at the enzyme site.

\section{INTRODUCTION}

The abundance of the different polyunsaturated precursors for the different types of prostaglandins (monoenoic, dienoic and trienoic) in human tissues has recently received more attention following reports of the low incidence of acute myocardial infarction in Eskimos in Greenland $(1,2)$. The markedly different pattern of fatty acid composition of the plasma lipids of Eskimos living in Greenland (3) relative to those living in Denmark strongly indicate beneficial effects of polyunsaturated acids derived from linolenate (e.g., timnodonic acid [20:5(n-3)] that are so abundant in the Eskimo maritime food)(4). A possible effect of linolenate in reducing coronary occlusion was reported and retracted 10 years earlier by Owren $(5,6,7)$. Dietary linolenate is rapidy converted in animal tissues to the long-chain forms, 
$20: 5,22: 5$ and $22: 6$, which are then accumulated in cellular glycerolipids. Thus, some antithrombotic effects reported (5) may be due to the longer $\mathrm{C}-20$ and $\mathrm{C}-22$ polyunsaturated derivatives of the $(n-3)$ Class of acids rather than the nutrient linolenate per se. Polyunsaturated acids of the $(n-3)$ type do not stimulate platelet aggregation $(8,9)$ in contrast to the dramatic action of arachidonate [20:4(n-6)] in producing stroke in rats (10) and sudden death in rabbits (II). This action of arachidonate seems due to its ability to form thromboxane $\mathrm{A}_{2}$ (12). The additional action of thromboxane $A_{2}$ in causing thrombosis and arterial vasospasm (12-14) gives further impetus to understanding the manner in which certain $\mathrm{C}-20$ and $\mathrm{C}-22$ polyunsaturated acids may influence these fatal cardiovascular events.

Dyerberg and Bang (1) indicated that the antiaggregatory action of 20:5(n-3) might be due to a competitive inhibition that prevents 20:4 from forming $\mathrm{TXA}_{2}$. This is in accord with an earlier report that fatty acids of the $(n-3)$ type were not effectively oxidized by cylooxygenase from sheep vesicular gland (15). The $(n-3)$ acids were bound to the active site with affinities ( 1.7 to $15 \mu \mathrm{M}$ ) equal to or greater than that for arachidonate and are thus effective competitive inhibitors (15). Moncada and vane (16) agreeing with this concept and citing the evidence by Raz (17) have concluded that the use of eicosapentaenoate could afford a "dietary protection against thrombosis". Nevertheless, they regarded the protection to be due primarily to the possibility that [20:5(n-3)] can be utilized by the vessel wall to make "an antiaggregating substance, probably a $\Delta^{1}{ }^{7}$-prostacyclin ( $\mathrm{PGI}_{3}$ )" and an accompaning thromboxane $A_{3}$ which is not a "proaggregatory agent". A recent report from Needleman's laboratory using $1{ }^{4} \mathrm{C}-20: 5$, emphasized the lower reaction rate with 20:5 (18) refocusing attention upon the ability of the $(n-3)$ type of acids to inhibit cyclooxygenase.

A variety of fatty acids may be oxidized via the cyclooxgenase enzyme, and as a result, it lacks absolute specificity [reviewed in (19)]. The possibility of an exceptionally potent $\mathrm{PGI}_{3}$ being formed in Eskimos raised again

the recurring question of whether or not trienoic prostaglandins occur to an appreciable extent in Nature. Toward that objective, we reexamined the ability of cyclooxygenase from sheep vesicular gland to oxidize $20: 5(n-3)$ and form the intermediate $\mathrm{PGH}_{3}$, necessary for subsequent prostacyclin or thromboxane production. Our results, confirming an important inhibitory role for the $(n-3)$ fatty acids, indicate a striking dependence of $\mathrm{PGH}_{3}$ biosynthesis upon the prevailing peroxide tone. 
Pure cyclooxygenase from sheep vesicular gland was prepared via DEAE cellulose and Bio-Gel column chromatography and isoelectric focusing as described earlier (20). The purified cyclooxygenase was dialyzed overnight in $0.2 \mathrm{M}$ phosphate buffer with $20 \%$ glycerol to remove phenol. Its concentration, expressed as nanomolar (nM), is based upon the subunit weight of 70,000 daltons (20). The activity of the enzyme was routinely determined polarigraphically in 3 $\mathrm{ml}$ reaction vessels containing $40 \mu \mathrm{M}$ arachidonate [20:4(n-6)] and $0.67 \mathrm{mM}$ phenol in $0.1 \mathrm{M}$ Tris-HCl (pH 8.5$)$ at $30 \pm 0.5^{\circ} \mathrm{C}$. Instantaneous velocities were monitored using a Yellow Springs Model 53 oxygen meter in conjunction with an electronic differentiator which provided a direct recording of the rate of oxygen utilization (2I) when testing the effectiveness of different substrates. After the reaction ceased due to enzymatic self-inactivation (22), a second addition of cyclooxygenase was made. Finally, excess lipoxygenase was added to the chamber to provide complete oxidation of the fatty acid and serve as control in making quantitative estimates of the extent of the reaction.

Eicosatrienoate $[20: 3(n-6)]$ and eicosatetraenoate [20:4 (n-6)] were obtained as 99\% pure from Nuchek Preps (Elysian, MN) and stored in toluene at $0^{\circ} \mathrm{C}$. The methyl ester of eicosapentaenoate $[20: 5(n-3)]$, obtained as $99 \%$ pure from Applied Sciences Lab (State College, PA) was saponified to obtain the free acid. The methyl ester was dissolved in methanol, $2.7 \mathrm{M} \mathrm{KOH}$ was added, and the solution was heated at $50^{\circ} \mathrm{C}$ for 30 minutes. The solution was acidified with formic acid and the free acid was extracted with pentane. The pentane solution was evaporated under nitrogen, and the residue dissolved in chloroform and stored at $5^{\circ} \mathrm{C}$. Aqueous solutions were prepared by evaporating aliquots of the stock acid solutions and dissolving the suspensions by vigorous shaking in 0.1M Tris-HCl buffer ( $\mathrm{pH} 8.5)$. The purity of each fatty acid used for enzymatic studies was confirmed by gas chromatography after converting it to the methyl ester derivative.

\section{RESULTS}

Using $10 \mu \mathrm{M}$ fatty acids in the standard assay conditions with $108 \mathrm{nM}$ cyclooxygenase, we observed utilization rates of 223 and $251 \mu \mathrm{M} / \mathrm{min}$ with $[20: 3(\mathrm{n}-6)]$ and $[20: 4(\mathrm{n}-6)]$, respectively, and 0 for $[20: 3(n-3)]$ and $[20: 5(n-3)]$. Table 1 illustrates further results for the two $(n-3)$ acids in comparison with $[20: 4(n-6)]$ in the presence and absence of $0.67 \mathrm{mM}$ phenol a peroxidase cosubstrate that helps lower the hydroperoxide content. Neither of the $(n-3)$ acids was effectively oxidized by $25 \mathrm{nM}$ cyclooxygenase in the presence 
of phenol, although they reacted completely with soybean lipoxygenase. In contrast to the $(n-3)$ acids, 3 and $10 \mu \mathrm{M}$ amounts of 20:4 (n-6) were completely oxidized by the first addition of cyclooxygenase, with the $30 \mu \mathrm{M}$ experiment indicating $16 \mu \mathrm{M}$ was oxidized per $25 \mathrm{nM}$ enzyme (about 650 moles per mole of enzyme). On the other hand, 20:3(n-3) was not oxidized significantly by cyclooxygenase under either condition. In the absence of phenol, the extent of oxidation of [20:4(n-6)] (about $4 \mu \mathrm{M}$, limited by enzymatic self-inactivation) was about

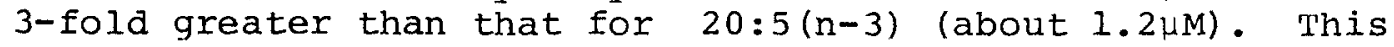
represents about 150 and 50 molecules of substrate oxidized per molecule of enzyme subunit for $20: 4(n-6)$ and $20: 5(n-3)$ respectively. Under these conditions, the [20:4(n-6)] reacted only twice as fast as the 20:5(n-3).

Table I. OXYGENATION OF POLYUNSATURATED FATTY ACIDS

\begin{tabular}{|c|c|c|c|}
\hline Fatty & \multirow{2}{*}{\multicolumn{3}{|c|}{ Cyclooxygenase }} \\
\hline Acid & & & \\
\hline $\begin{array}{l}\text { Added } \\
(\mu M)\end{array}$ & $\begin{array}{cc}\text { Rate } & \text { Extent } \\
(\mu \mathrm{M} / \mathrm{min}) & (\mu \mathrm{M})\end{array}$ & $\begin{array}{l}\text { Rate Cumulative Extent } \\
(\mu \mathrm{M} / \mathrm{min}) \quad(\mu \mathrm{M})\end{array}$ & $\begin{array}{c}\text { Final Extent } \\
(\mu M)\end{array}$ \\
\hline
\end{tabular}

$\begin{array}{cccc}20: 3(\mathrm{n}-3) & & \text { Results with } 0.67 \mathrm{mM} \\ 3 & 0 & 0 & 0 \\ 10 & 0 & 0 & 0 \\ 30 & 0 & 0 & 0 \\ 20: 4(\mathrm{n}-6) & & & \\ 3 & 56 & 2.9 & \\ 10 & 60 & 9.5 & 77 \\ 30 & 77 & 16.2 & \\ 20: 5(\mathrm{n}-3) & & & \\ 3 & 0 & 0 & 0 \\ 10 & 0 & 0 & 0 \\ 30 & 0 & 0 & \end{array}$

$\begin{array}{ccc}20: 3(n-3) & & \\ 3 & 0 & 0 \\ 10 & 0 & 0 \\ 30 & 0 & \\ 20: 4(n-6) & & 3.2 \\ 3 & 35 & 4.4 \\ 10 & 38 & 4.0 \\ 30 & 38 & 1.2 \\ 20: 5(n-3) & & 1.4 \\ 3 & 17 & 1.2 \\ 10 & 21 & 1.2 \\ 30 & 21 & 17 \\ 60 & 17 & \end{array}$

0.6

0

0

0

31

31

14

14

21

14
0.12

0

0.5

2. 9

9.5

29.5

0

0

0

$$
3.0
$$

9.7

30.2

$$
\begin{array}{r}
2.9 \\
9.5 \\
29.5
\end{array}
$$

3

10.7

32 
Table II. OXYGENATION OF POLYUNSATURATED FATTY ACIDS

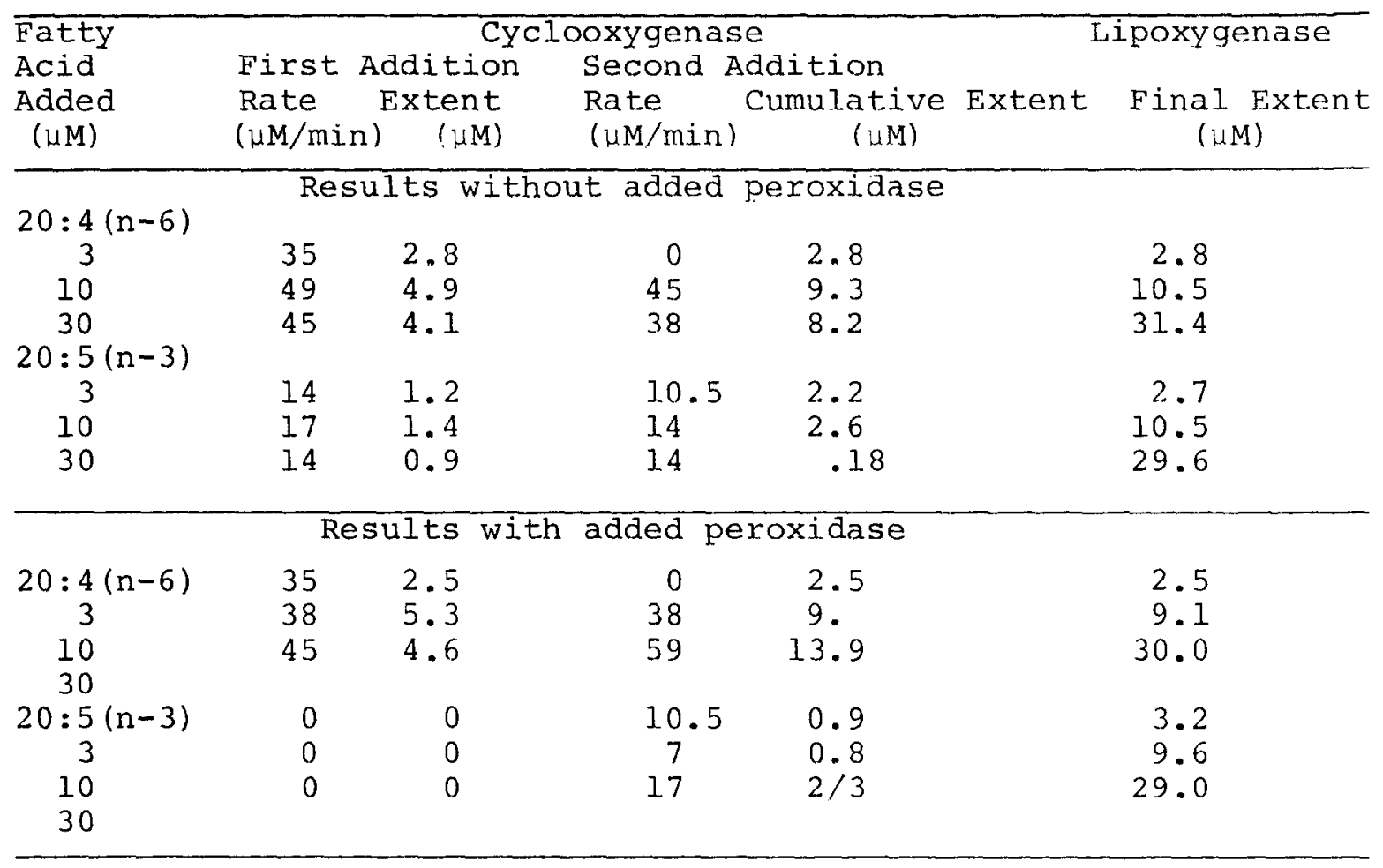

To examine the effect of peroxide tone upon the selectivity of the cyclooxygenase reaction, a moderate amount of glutathione peroxidase was added to systems containing $0.5 \mathrm{~mm}$ glutathione to remove any excess hydroperoxides from the system. The amount of peroxidase added (5,000 units) was not enough to significantly inhibit the oxidation of $20: 4-$ $(n-6)$ in the absence of phenol or to inhibit the reaction of lipoxygenase with the acids. The results without added peroxidase (Table II) agreed well with those in experiments in Table I, with 20:4(n-6) reacting twice as fast as 20:5$(n-3)$ and to about a 3-fold greater extent. In the presence of glutathione peroxidase, however, 20:5(n-3) was ineffective until the second addition of enzyme, where the extent of reaction with $30 \mu \mathrm{M}$ substrate was much greater with the second addition.

\section{DISCUSSION}

Our results indicate that the peroxide tone can have a dramatic influence upon the specificity of cyclooxygenase action. Oxidation of $20: 5(n-3)$ does not proceed well in the presence of either the peroxidase cosubstrate, phenol, 
or with an active glutathione peroxidase system. The level of peroxidase activity used in our in vitro studies was much less than that present in liver cells in vivo, and its effective inhibition suggest that similar inhibition would occur in many other tissues. This phenomenon may have a decisive role in suppressing the conversion of eicosapentaenoic acid [20:5(n-3)] into the trienoic prostaglandin derivative in vivo. A relatively low degree of conversion would be in accord with the finding that the (n-3) fatty acids can not relieve the inadequate reproductive capacity of rats deficient in essential fatty acids $(23-25)$. The different cyclooxygenase specificities that we have observed help highlight the need to examine cyclooxygenase activity under conditions similar to those that occur in vivo rather than systems with high peroxide contents generated in vitro $(26,27)$. In particular, the formation of trienoic prostaglandin derivatives in a tissue may prove to be a very sensitive indicator of the prevailing abundance of peroxides. It may occur to a greater extent in phagocytic cells that generate high peroxide tone.

Previous inhibitory studies with the $(n-3)$ class of fatty acids (15) were performed with added $0.67 \mathrm{mM}$ phenol, and showed only the competitive reversible effect. We now recognize some conditions under which such acids may be oxygenated and thereby cause irreversible inactivation of the cyclooxygenase. The inactivating conditions may have been obtained in incubations described earlier by Pace-Asciak and Wolfe (28) We have also observed a self-catalyzed inactivation with a variety of $(n-6)$ fatty acids even in the presence of phenol (15). Inactivation with 20:2(n-6) occurred with only oneeighth the total oxygenation occurring with $20: 4(n-6)$ (29).

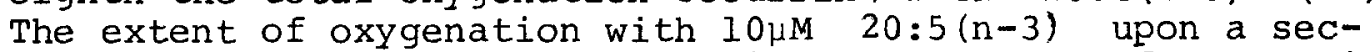
ond addition of enzyme $(0.9 \mu \mathrm{M})$ in the presence of glutathione peroxidase (see Table II) indicates that when peroxides were low, but not totally absent, the 20:5 caused inactivation of the cyclooxygenase with little oxygenation occurring. An interesting possibility derives from these results. When peroxide tone is extremely low, 20:5 will be a reversible competitive inhibitor of arachidonate conversion to prostaglandins. However, when a slight elevation in peroxide levels occurs - perhaps via rapid 20:4 oxygenation to $\mathrm{PGG}_{2}$ then the $20: 5$ becomes also an irreversible inactivator which could very effectively suppress the 20:4 oxidation. The ability to inactivate the cyclooxygenase with little or no detectable oxygen consumption in our assay system is similar to results obtained with acetylenic analogs $(30,31)$. Apparently small amounts of peroxide are sufficient to allow these acids to promote the self-inactivation (22) that will not occur at all in the absence of peroxides $(30,32)$. Without knowing more about the levels of cyclooxygenase activity 
and the steady state levels of lipid peroxides, it is difficult to determine whether the $(n-3)$ class of acid and the acetylenic analogs achieve their inhibitory effects in vivo by reversible competitive action or by irreversibly inactivating the cyclooxygenase. Nevertheless, such acids are clearly inhibitors of the conversion of arachidonate to its products. Thus, although the proposed beneficial role of dietary eicosapentaenoic acid might lie in forming vasoactive, antiaggregating autacoids, a general inhibitory role encompassing both reversible and irreversible actions appears more likely.

\section{ACKNOWLEDGMENTS}

This work was supported in part by a grant (PCM7824078) from the National science Foundation. 
1. Dyerberg, J., Bang, H.O. (1978) Dietary Fat and Thrombosis, Lancet $\underline{i}, 152$

2. Dyerberg, J., Bang, H.O., Stoffersen, E., Moncada, S., Vane, J.R. (1978) Eicosapentaenoic Acid and prevention of Thrombosis and Atherosclerosis, Lancet ii, 117

3. Dyerberg, J., Bang, H.O., Hjørne, N. (1975) Fatty Acid Composition of the Plasma Lipids in Greenland Eskimos, Amer. J. Clin. Nutrition 28, 958

4. Bang, H.O., Dyerberg, J., Hjørne, N. (1976) Composition of Food Consuned by Greenland Eskimos, Acta Med. Scand 200,69

5. Owren, P.A., Hellem, A.J., Odegaard, A. (1964) Linolenic Acid for the prevention of Thrombosis and Myocardial Infarction, Lancet ii, 975

6. Owren, P.A. (1965) Coronary Thrombosis. Its Mechanism and possible Prevention by Linolenic Acid, Annls. Int. Med. 63,167

7. Uwren, P.A. (1965) Linoleic Acid and Coronary Thrombosis, Annls. Int. Med. 63,1160

8. Willis, A.L. (1974) An Enzymatic Mechanism for the Antithrombotic and Antihemostatic Actions of Aspirin, Science 183,325

9. Silver, M.J., Smith, J.B., Ingerman, C., Kocsis, J.J. (1973) Arachidonic Acid-Induced Human Platelet Aggregation and Prostaglandin Formation, Prostaglandins $\underline{4}, 863$

10. Furlow, T.W., Jr., Bass, N.H. (1975) stroke in Rats Produced by Carotid Injection of Sodium Arachidonate, Science 187,658

11. Silver, M.J., Hoch, W., Kocsis, J.J., Ingerman, C.M., Smith, J.B. (1974) Arachidonic Acid Causes Sudden Death in Rabbits, Science 183, 1085

12. Hamberg, M., Svensson, J., Samuelsson, B. (1975) Thromboxanes: A New Group of Biologically Active Compounds Derived from Prostaglandin Endopoeroxides, Proc. Nat. Acad. SCi. USA $\underline{72}, 2994$

13. Svensson, J., Hamberg, M. (1976) Thromboxane $A_{2}$ and Prostaglandin $\mathrm{H}_{2}$ : Potent Stimulators of the Swine Coronary Artery, Prostaglandins 12, 943 
14. Ellis, E.F., Oelz, O.,Roberts, L.J., Payne, N.A., Sweetman, B.J., Nies, A.S., Oates, J.A. (1976) Coronary Arterial Smooth Muscle Contraction by a Substance Released from Platelets: Evidence That it is Thromboxane $A_{2}$, Science 193, 1135

15. Lands, W.E.M., LeTellier, P.E., Rome, L.H., Vanderhoek, J.Y. (1973) Inhibition of Prostaglandin Biosynthesis, Adv. in Biosclences 9, 15

16. Moncada, S., Vane, J.R., (1979) The Role of Prostacyclin in Vascular Tissue, Fed. Proc. 38, 66

17. Raz, A., Minkes, M.S., Needlernan, P. (1977) Éndoperoxides and Thromboxanes. Structural Determinants for platelet Aggregation and Vasoconstriction, Biocnem. Biophys. Acta. $\underline{488}, 305$

18. Needleman, P., Raz, A., Minkes, M.S., Ferrendelli, J.A., Sprecher, H. (1979) Triene Prostaglandins: Prostacyclin and Thromboxane Biosynthesis and Unique Biological properties, Proc. Nat. Acad. Sci. 76, 944

19. Lands, W.E.M., Heinier, M.E., Crawiord, C.G. (1977) Function of Polyunsaturated Fatty Acids: Biosynthesis of Prostaglandins, in Polyunsaturated Fatty Acids, (Kunau, W.H., and Holman, R.T., eds.) Amer. Oil Chem. Soc., Champaign, IL, 193

20. Hemler, M.E. Lands, W.E.M., Smith, W.L., (1976) Purification of the Cyclooxygenase l'hat Forms Prostaglandins. Demonstration of 'lwo Forms of Iron in the Holoenzyme, J. Bio1. Chem. 261, 5575

21. Cook, H.W., Ford, G., Lands, W.E.M., (19\%) Instrumental Improvements for Rapid, Detailed Kinetic Studies of oxygenase Activity, Anal. Biochem. 96, 341

22. Smith, W.L., Lands, W.E.M. (1972) oxygenation of Polyunsaturated Fatty Acids During Biosynthesis by sheep Vesicular Gland, Biochem., 11, 3276

23. Quackenbush, F.W., Kummerow, F.A., Steenbock, H. (1942) The Effectiveness of Linoleic, Arachidonic, and Linolenic Acids in Reproduction and Lactation, J. Nutr., 24, 213

24. Deue1, H.J., Martin, C.R., Alfin-Slater, R.E. (1954) The Effect of Fat Level of the Diet on General Nutrition, I. Nutr. $\underline{54}, 193$ 
25. Privett, O.S., Aaes-Jørgenson, E., Holman, R.Y., Lundberg, W.O. (1958) The Effect of Concentrates of Polyunsaturated Acids from Tuna Oil Upon Essential Fatty Acids Deficiency, J. Nutr. 67, 423

26. Cook, H.W., Lands, W.E.M. (1976) Mechanism for Suppression of Cellular Biosynthesis of Prostaglandins, Nature 260,630

27. Hemler, M.E., Cook, H.W., Lands, W.E.M. (1979) Prostaglandin Biosynthesis Can be Triggered by Lipid Peroxides. Arch. Biochem. Biophysics 193, 340

28. Pace-Asciak, C., Wolfe, L.S. (1968) Inhibition of Prostaglandin Synthesis by Oleic, Linoleic and Linolenic Acids, Biochem. Biophys. Acta 152, 784

29. Hemler, M.E., Crawford, C.G., Lands, W.E.M. (1978) Lipooxygenation Activity of Purified Prostaglandin-Forming Cyclooxygenase, Biochem. 17, 1772

30. Vanderhoek, J.Y., Lands, W.E.M. (1973) Acetylenic Inhibitors of Sheep Vesicular Gland Oxygenase, Biochem. Biophys Acta 296,374

31. Lands, W.E.M., LeTellier, P.R., Rome, L.H., Vanderhoek, J.Y. (1974) Regulation of Prostaglandins Synthesis in Prostaglandin Synthetase Inhibitors (Robinson, H.J., ed.) Raven Press, N.Y.

32. Vanderhoek, J.Y., Lands, W.E.M. (1978) Evidence for $\mathrm{H}_{2} \mathrm{O}_{2}$ Mediating the Irreversible Action of Acetylemic Inhibitors of Prostaglandin Biosynthesis, Prostaglandins and Medicine, 1, 251 